\title{
Parameters Expediting the Thermal Conversion of Ba-Exchanged Zeolite A to Monoclinic Celsian
}

\author{
A. Marocco, M. Pansini, G. Dell'Agli, and S. Esposito \\ Laboratorio Materiali del Dipartimento di Meccanica, Strutture, Ambiente e Territorio, \\ Facoltà di Ingegneria dell'Università di Cassino, Via G. Di Biasio 43, Cassino, 03043 Frosinone, Italy \\ Correspondence should be addressed to M. Pansini, pansini@unicas.it
}

Received 27 July 2010; Accepted 28 October 2010

Academic Editor: David Cann

Copyright (C) 2010 A. Marocco et al. This is an open access article distributed under the Creative Commons Attribution License, which permits unrestricted use, distribution, and reproduction in any medium, provided the original work is properly cited.

Four samples of Ba-exchanged zeolite A, bearing small residual amounts of $\mathrm{Na}(0.27,0.43,0.58$, and 0.74 meq/g), were thermally treated in the temperature range $200-1500^{\circ} \mathrm{C}$ for times up to 28 hours. The same samples were pressed at 30 and $60 \mathrm{MPa}$ to form cylindrical pellets which were thermally treated at $1300^{\circ} \mathrm{C}$ for 5 hours. All materials were characterized by room temperature XRD. The sequence of thermal transformations that Ba-exchanged zeolite A undergoes (zeolite $\rightarrow$ amorphous phase $\rightarrow$ hexacelsian $\rightarrow$ monoclinic celsian) and the strong mineralizing action developed by $\mathrm{Na}$ are confirmed. Pressing the Ba-exchanged zeolite $\mathrm{A}$ powder-like samples to obtain cylindrical pellets is found to expedite the sluggish final phase transition hexacelsian $\rightarrow$ monoclinic celsian. The optimum residual $\mathrm{Na}$ content of Ba-exchanged zeolite A for transformation into monoclinic celsian is assessed to be between 0.27 and $0.43 \mathrm{meq} / \mathrm{g}$.

\section{Introduction}

1.1. Uses of Monoclinic Celsian. Monoclinic celsian $\left(\mathrm{BaAl}_{2}\right.$ $\left.\mathrm{Si}_{2} \mathrm{O}_{8}\right)$ is used as a refractory, high temperature electrical insulator, or as a substrate for integrated circuits because of its good thermal and electrical properties [1]. Innovative studies suggest the use of monoclinic celsian in aeronautic and aerospace field, as matrix material for reinforcement with continuous ceramic fibers of high temperature structural composites to be used in hot sections of turbine engines $[1-11]$ and in the field of radomes $[12,13]$.

1.2. Problems in Preparation. The synthesis of monoclinic celsian gives rise to considerable problems [14]. On one hand, it requires high temperatures and/or long reaction times, which give rise to high process costs. On the other hand, the first polymorph to nucleate is hexagonal celsian (hexacelsian) although it is thermodynamically stable at temperatures higher than $1590^{\circ} \mathrm{C}$ [15]. This behaviour was ascribed to the simpler crystal structure of the high symmetry modification presenting a lower kinetic barrier to nucleation [16].
The early crystallisation of hexacelsian appears to be a serious drawback for two reasons. On one hand, hexacelsian cannot be used as a refractory because it, at $300^{\circ} \mathrm{C}$, undergoes a reversible transformation into an orthorhombic form accompanied by a detrimental $(\geq 3 \%)$ volume change [15]. On the other hand, the transformation of hexacelsian to monoclinic celsian occurs only after prolonged heating (more than 20 hours) at temperatures higher than $1500^{\circ} \mathrm{C}$ in the presence of mineralizers and monoclinic seed particles [17].

A long-term study [14, 18-25] concerning the thermal transformation of Ba-exchanged zeolites into monoclinic celsian was undertaken. This study started from the work of Subramanian and coworkers [26-29] who crystallised alkaline-earth and alkaline framework aluminosilicates, which belong to the class of the feldspars, by thermal treatment of cation exchanged zeolites at temperatures slightly higher than $1000^{\circ} \mathrm{C}$ for some hours. The technique proposed by Subramanian and coworkers [26-29] appeared to be an interesting way of avoiding the drawbacks arising in the traditional syntheses of monoclinic celsian [14]. Actually very interesting results were obtained in the study concerning 
the thermal transformation of Ba-exchanged zeolites into monoclinic celsian [14, 18-25]. In particular, it was found that, upon a thermal treatment at temperatures higher than $1000^{\circ} \mathrm{C}, \mathrm{Ba}$-exchanged zeolite $\mathrm{A}$, which after dehydration exactly has the stoichiometric composition of celsian, gave rise to the following sequence of transformations: zeolite $\rightarrow$ amorphous phase $\rightarrow$ hexacelsian $\rightarrow$ monoclinic celsian. Moreover, it was found that thermal treatments at $1100^{\circ} \mathrm{C}$ for 6 hours [14] and $1300^{\circ} \mathrm{C}$ for 22 hours [18] were sufficient to transform samples of Ba-exchanged zeolite $\mathrm{A}$, containing $0.58 \mathrm{meq} / \mathrm{g}$ and $0.20 \mathrm{meq} / \mathrm{g} \mathrm{Na}$ (residual amount), respectively, into fully monoclinic celsian. These data reveal that $\mathrm{Ba}$-exchanged zeolite A does appear to be a very reactive precursor inasmuch as the full conversion into monoclinic celsian was obtained at far milder conditions than those reported in the literature (heating for more than 20 hours at temperatures higher than $1500^{\circ} \mathrm{C}$ ) [14].

Nevertheless, this study revealed that the temperatures and duration times of thermal treatments necessary to attain the full conversion of samples of Ba-exchanged zeolite A into monoclinic celsian are strongly dependent on the residual $\mathrm{Na}$ content of various zeolite A samples.

1.3. Objectives of this Work. This investigation aims at ascertaining to what extent this parameter affects the thermal transformations that $\mathrm{Ba}$-exchanged zeolite $\mathrm{A}$ undergoes. To fulfil this goal, four zeolite A samples bearing 0.27, 0.43, 0.58 , and $0.74 \mathrm{meq} / \mathrm{g} \mathrm{Na}$ (residual content) were prepared by cation exchange and their thermal transformations were investigated by room temperature X-ray diffraction and differential thermal analysis. Such $\mathrm{Na}$ residual contents were selected on the basis of the following considerations. In a previous paper, [18] a sample of Ba-exchanged zeolite A with $0.20 \mathrm{meq} / \mathrm{g} \mathrm{Na}$ residual content was prepared. It was found very difficult to further reduce such Na residual content as $0.12 \mathrm{meq} / \mathrm{g} \mathrm{Na}$ were shown to be related to $\mathrm{NaAlO}_{2}$ occluded in its $\beta$-cages (sodalite cages), similar to feldspathoid behavior [30]. It appeared very likely that $\mathrm{Na}$ arising from the occlusion of $\mathrm{NaAlO}_{2}$ in the $\beta$-cages could not be practically removed and, thus exchangeable $\mathrm{Na}(0.08 \mathrm{meq} / \mathrm{g})$ still present after the last Ba-exchange was between 1 and $2 \%$ of the $\mathrm{Na}$ originally present in the zeolite framework (the real initial $\mathrm{Na}$ content of zeolite A was $5.60 \mathrm{meq} / \mathrm{g}$ [18]). Moreover, it was reported that, for this sample, 22-, 15- and 22-hour thermal treatments at 1300, 1400 , and $1500^{\circ} \mathrm{C}$, respectively, were sufficient to attain the full conversion of hexacelsian into monoclinic celsian. Thus $0.27 \mathrm{meq} / \mathrm{g}$ was selected as it is an Na residual amount slightly higher than the value considered as a limit $(0.20 \mathrm{meq} / \mathrm{g})$, for which temperature and time of the thermal treatments necessary to attain the full conversion of hexacelsian to monoclinic are well known. The remaining $\mathrm{Na}$ residual amounts $(0.43,0.58$ and $0.74 \mathrm{meq} / \mathrm{g})$ were selected as they steadily increase starting from $0.27 \mathrm{meq} / \mathrm{g}$ so as to cover the whole range of $\mathrm{Na}$ residual amount which could be accepted as an impurity in a celsian based ceramic manufactured by this technique.

This work also aims at attaining a second goal. Actually the thermal transformation of compacts obtained by pressing powder-like samples of Ba-exchanged zeolite A appears very interesting inasmuch as it exhibits potential for practical applications in the manufacture of celsian based ceramics. Thus the role played by the forming pressure of compacts on the thermal transformation of Ba-exchanged zeolite $\mathrm{A}$ is investigated by cold pressing the various powder-like samples of zeolite $\mathrm{A}$ at 30 and $60 \mathrm{MPa}$. These compacts were subjected to the same thermal treatments as the powder-like samples and then investigated by room temperature $\mathrm{X}$-ray diffraction in order to compare these results.

\section{Experimental}

2.1. Ion Exchange with $\mathrm{Ba}^{2+}$. Carlo Erba reagent grade synthetic zeolite $4 \mathrm{~A}\left(\mathrm{Na}_{12} \mathrm{Al}_{12} \mathrm{Si}_{12} \mathrm{O}_{48} \cdot 27 \mathrm{H}_{2} \mathrm{O}\right)$ was subjected to various cation exchange operations in order to obtain four samples of Ba-exchanged zeolite A bearing different residual amounts of $\mathrm{Na}$. The samples which will be identified from this point onwards as $1,2,3,4$ were obtained according to the procedures hereafter described.

Sample 1. Original zeolite $4 \mathrm{~A}$ in its $\mathrm{Na}$ form was contacted overnight with a warm $\left(60-70^{\circ} \mathrm{C}\right)\left[\mathrm{Ba}^{2+}\right]=0.2 \mathrm{~N}$ solution at a weight solid/liquid ratio $(S / L)=1 / 20$. The solid was separated from the liquid through filtration and again contacted with fresh exchange solution for a total of nine times.

Sample 2. Original zeolite $4 \mathrm{~A}$ in its $\mathrm{Na}$ form was contacted overnight with a warm $\left(60-70^{\circ} \mathrm{C}\right)\left[\mathrm{Ba}^{2+}\right]=0.2 \mathrm{~N}$ solution at a weight solid/liquid ratio $(S / L)=1 / 20$. The solid was separated from the liquid through filtration and again contacted with fresh exchange solution for a total of five times.

Sample 3. Original zeolite $4 \mathrm{~A}$ in its $\mathrm{Na}$ form was contacted overnight with a warm $\left(60-70^{\circ} \mathrm{C}\right)\left[\mathrm{Ba}^{2+}\right]=0.5 \mathrm{~N}$ solution at a weight solid/liquid ratio $(\mathrm{S} / \mathrm{L})=1 / 20$.

Sample 4. Original zeolite $4 \mathrm{~A}$ in its $\mathrm{Na}$ form was contacted overnight with a warm $\left(60-70^{\circ} \mathrm{C}\right)\left[\mathrm{Ba}^{2+}\right]=0.2 \mathrm{~N}$ solution at a weight solid/liquid ratio $(\mathrm{S} / \mathrm{L})=1 / 20$. The solid was separated from the liquid through filtration and again contacted with fresh exchange solution for a total of two times.

The exchange solutions (initial $\mathrm{pH}$ about 6.3) were prepared using doubly distilled water and Carlo Erba reagentgrade $\mathrm{Ba}\left(\mathrm{NO}_{3}\right)_{2}$ (purity $99.5 \%$ ). The $\mathrm{pH}$ of the suspensions zeolite $\mathrm{A}-\mathrm{Ba}^{2+}$ solutions ranged between 6.9 and 7.0.

The residual Na content of the different zeolite samples intermediate and total was determined by the following procedure. The zeolite was chemically dissolved in a hydrofluoric and perchloric acid solution and its $\mathrm{Na}^{+}$concentration was determined by atomic absorption spectrophotometry (AAS), using a Perkin-Elmer AAnalyst 100 apparatus. The consistency of concentration measurements related to cation 
TABLE 1: Thermal treatments done to all four Ba-exchanged zeolite A samples and the figures in which the corresponding XRD patterns are shown.

\begin{tabular}{lc}
\hline Temp $\left({ }^{\circ} \mathrm{C}\right)$ & Thermal treatment ${ }^{\mathrm{a}}(\mathrm{h})$ \\
\hline 200 & 2 (Figure $1(\mathrm{a}))$ \\
500 & 0 (Figure $1(\mathrm{~b}))$ \\
800 & 28 (Figure $1(\mathrm{c}))$ \\
1000 & 5 (Figure 2$)$ \\
1100 & 5,10 \\
1200 & 5 \\
1300 & 5 (Figure 3$), 10,15$ \\
1400 & 5 \\
1500 & 5 \\
\hline
\end{tabular}

${ }^{\mathrm{a}}$ The samples were heated at a rate of $10^{\circ} \mathrm{C} / \mathrm{min}$ up to the reported temperature, kept at that temperature for the reported time, and allowed to cool in air.

TABle 2: Composition of the products.

\begin{tabular}{|c|c|c|c|c|}
\hline Sample & $\mathrm{Na}$ (meq/g) & $\mathrm{X}_{\mathrm{Na}}{ }^{\mathrm{a}}$ & $\mathrm{Na}_{2} \mathrm{O}$ w. $\%^{\mathrm{b}}$ & Chemical formula $^{\mathrm{b}, \mathrm{c}}$ \\
\hline 1 & 0.27 & 0.05 & 0.84 & $\mathrm{Ba}_{0.950} \mathrm{Na}_{0.100} \mathrm{Al}_{2} \mathrm{Si}_{2} \mathrm{O}_{8}$ \\
\hline 2 & 0.43 & 0.08 & 1.33 & $\mathrm{Ba}_{0.921} \mathrm{Na}_{0.158} \mathrm{Al}_{2} \mathrm{Si}_{2} \mathrm{O}_{8}$ \\
\hline 3 & 0.58 & 0.10 & 1.80 & $\mathrm{Ba}_{0.894} \mathrm{Na}_{0.212} \mathrm{Al}_{2} \mathrm{Si}_{2} \mathrm{O}_{8}$ \\
\hline 4 & 0.74 & 0.13 & 2.29 & $\mathrm{Ba}_{0.866} \mathrm{Na}_{0.268} \mathrm{Al}_{2} \mathrm{Si}_{2} \mathrm{O}_{8}$ \\
\hline
\end{tabular}

exchange operations was checked by determining $\mathrm{Ba}^{2+}$ concentration by titration with EDTA using erio $\mathrm{T}$ as the indicator and an $\mathrm{NH}_{3}$ and $\mathrm{NH}_{4}^{+}$solution at $\mathrm{pH} 10$ as buffer [31].

The resulting powders were washed with doubly distilled water, dried overnight at $80^{\circ} \mathrm{C}$ and stored for at least 3 days in an environment having about 50\% relative humidity to allow water saturation of zeolite.

2.2. Thermal Treatments. Ba-exchanged zeolite A samples, obtained according to the procedures previously described, were subjected to various thermal treatments in a Lenton furnace, which ensures stable temperature to within $\pm 2^{\circ} \mathrm{C}$, using $\mathrm{Al}_{2} \mathrm{O}_{3}$ crucibles. The thermal treatments, which are summarised in Table 1, were all done in air atmosphere. They were performed as follows. In some cases, the samples were heated at a rate of $10^{\circ} \mathrm{C} / \mathrm{min}$ up to the fixed temperature and subsequently cooled to room temperature. In the other cases, the samples were heated at a rate of $10^{\circ} \mathrm{C} / \mathrm{min}$ up to the fixed temperature, kept at this temperature for the fixed time, and subsequently cooled to room temperature.

These products were characterised by X-ray diffraction at room temperature using a Philips X'PERT diffractometer with $\mathrm{Cu} \mathrm{K} \alpha$ radiation and $10^{\circ}<2 \theta<60^{\circ}$ with a step width $2 \theta$ equal to $0.02^{\circ}$ and $1 \mathrm{~s}$ data collection per step.

The various $\mathrm{Ba}$-exchanged zeolite A samples were also characterised by simultaneous differential thermal analysis (DTA) and thermogravimetric analysis (TGA), using a Netzsch thermoanalyser model STA 409 with $\alpha-\mathrm{Al}_{2} \mathrm{O}_{3}$ as a reference and a $10^{\circ} \mathrm{C} / \mathrm{min}$ heating rate.
The cation composition of the final products of the thermal treatments, summarized in Table 2, were determined as follows. The various samples of Ba-exchanged zeolites A were thermally treated at $950^{\circ} \mathrm{C}$ for 2 hours in order to obtain the thermal collapse of the microporous zeolite structure and their irreversible dehydration. These thermally treated samples were chemically dissolved in the same hydrofluoric and perchloric acid solution and their $\mathrm{Na}^{+}$ concentrations were measured according to the procedure previously described.

2.3. Preparation of the Compacts. The powder-like Baexchanged zeolite A samples were used to prepare compacts according to the following procedure. Various zeolite powders were added with 6 weight \% doubly distilled water and then pressed with an uniaxial laboratory press at 30 or $60 \mathrm{MPa}$ to obtain cylindrical pellets (diameter $=15 \mathrm{~mm}$, height $=5 \mathrm{~mm}$ ). These pellets were dried at $105^{\circ} \mathrm{C}$ for 24 hours. Subsequently, the pellets were thermally treated in the previously described Lenton furnace according to the following thermal cycle:

(1) heating from room temperature to $500^{\circ} \mathrm{C}$ with a heating rate of $5^{\circ} \mathrm{C} / \mathrm{min}$,

(2) heating from 500 to $1300^{\circ} \mathrm{C}$ with a heating rate of $10^{\circ} \mathrm{C} / \mathrm{min}$,

(3) 5 hours at $1300^{\circ} \mathrm{C}$,

(4) cooling from 1300 to $800^{\circ} \mathrm{C}$ with a cooling rate of $20^{\circ} \mathrm{C} / \mathrm{min}$,

(5) cooling from $800^{\circ} \mathrm{C}$ to room temperature in air.

Subsequently these pellets were ground to fine powders which were characterised by X-ray diffraction at room temperature according to the modalities previously described.

\section{Results}

3.1. Cation Exchange. Data concerning cation exchange operations and, thus, cation composition of various zeolite A samples are summarized in Table 2. The residual $\mathrm{Na}$ content of various zeolite A samples is reported in the second column, whereas the Na equivalent fraction $\left(\mathrm{x}_{\mathrm{Na}}\right)$ was in the third. These values were calculated with respect to the real initial Na content of Carlo Erba reagent-grade zeolite A. This quantity, which was experimentally determined in previous work [18], was $5.60 \mathrm{meq} / \mathrm{g}$.

In the same Table 2 the $\mathrm{Na}_{2} \mathrm{O} \%$ weight of samples $1,2,3$, and 4 thermally treated at $950^{\circ} \mathrm{C}$ for 2 hours are reported. These values were used to calculate the chemical formula of celsian which can be obtained through the thermal treatments of samples 1, 2, 3, and 4. Such chemical formulae are reported in the final column of Table 2.

3.2. X-Ray Diffraction. XRD patterns of sample 1 thermally treated at $200^{\circ} \mathrm{C}$ for 2 hours, heated at $500^{\circ} \mathrm{C}$, and then cooled down in air atmosphere and thermally treated at $800^{\circ} \mathrm{C}$ for 28 hours are reported in Figure 1 together with the spectral lines of monoclinic celsian (JCPDS card n. 38-1450). 
The thermal treatment at $200^{\circ} \mathrm{C}$ for 2 hours resulted in the thermal collapse of the microporous zeolitic structure with the consequent formation of an amorphous phase. In the XRD pattern of sample 1 heated at $500^{\circ} \mathrm{C}$, and then cooled down in air atmosphere the presence of extremely broad diffraction peaks, which can be ascribed to monoclinic celsian, may be recorded. XRD patterns of samples 1 thermally treated at $800^{\circ} \mathrm{C}$ for 28 hours closely resembles XRD diffraction pattern of sample 1 , heated at $500^{\circ} \mathrm{C}$ and then cooled down in air atmosphere, which shows that thermal treatment at $800^{\circ} \mathrm{C}$ for 28 hours does not result in a sensible increase of the extent to which the crystallization of any phase occurs. The XRD patterns of samples 2, 3, and 4 thermally treated at 200 for 2 hours, heated at $500^{\circ} \mathrm{C}$ and then cooled down in air atmosphere, and thermally treated at $800^{\circ} \mathrm{C}$ for 28 hours are not reported as they closely resemble the homologous XRD pattern of sample 1.

The XRD pattern of samples 1, 2, 3, and 4 thermally treated at $1000^{\circ} \mathrm{C}$ for 5 hours are reported in Figure 2. In the XRD pattern of sample 1 sharp peaks of hexacelsian appear together with peaks of monoclinic celsian whose intensity is slightly higher than the intensity of peaks of monoclinic celsian recorded after thermally treating sample 1 at $800^{\circ} \mathrm{C}$ for 28 hours (Figure $1(\mathrm{c})$ ). The intensity of peaks of hexacelsian decreases with increasing $\mathrm{Na}$ residual content of Ba-exchanged zeolite $\mathrm{A}$, attains a minimum in sample 3, and then increases again in sample 4. In Figure 2 and in the following ones, the main diffraction peaks of hexacelsian and monoclinic celsian are denoted with $\mathrm{H}$ and $M$, respectively. An opposite trend may be detected by examining the intensity of peaks of monoclinic celsian which increases with increasing $\mathrm{Na}$ residual content of $\mathrm{Ba}-$ exchanged zeolite A, attains a maximum in sample 3 , and then decreases again in sample 4 . It must be noticed that in the XRD pattern of sample 4 a very low intensity peak (denoted with S), indicating the presence of a small amount of the sodium aluminosilicate known as low carnegieite $\left(\mathrm{NaAlSiO}_{4}\right.$ ) (JCPDS card n. 33-1203), may be detected. The attribution of the peak at $21^{\circ} 2 \theta$ to low carnegieite was performed on the basis of the following considerations. Zeolite $\mathrm{A}$ in its original $\mathrm{Na}$ form was subjected to a $5 \mathrm{~h}$ thermal treatment at $1300^{\circ} \mathrm{C}$ which resulted in the crystallization of low carnegieite, whose peak of highest intensity is located exactly at $21^{\circ} 2 \theta$. The remaining peaks of low carnegieite may not be immediately detected in the Figure 2 on account of the following reasons:

(a) they superimpose with peaks of monoclinic celsian or hexacelsian;

(b) their intensity is too weak due to the low amount of crystallized carnegieite.

XRD pattern of various samples thermally treated at $1100^{\circ} \mathrm{C}$ for 5 and 10 hours (not reported) and thermally treated at $1200^{\circ} \mathrm{C}$ for 5 hours (not reported) resembles the XRD pattern of homologous samples thermally treated at $1000^{\circ} \mathrm{C}$ for 5 hours. The only difference that can be noticed by comparing these XRD patterns is that the intensity of peaks of hexacelsian decreases and the intensity of peaks of

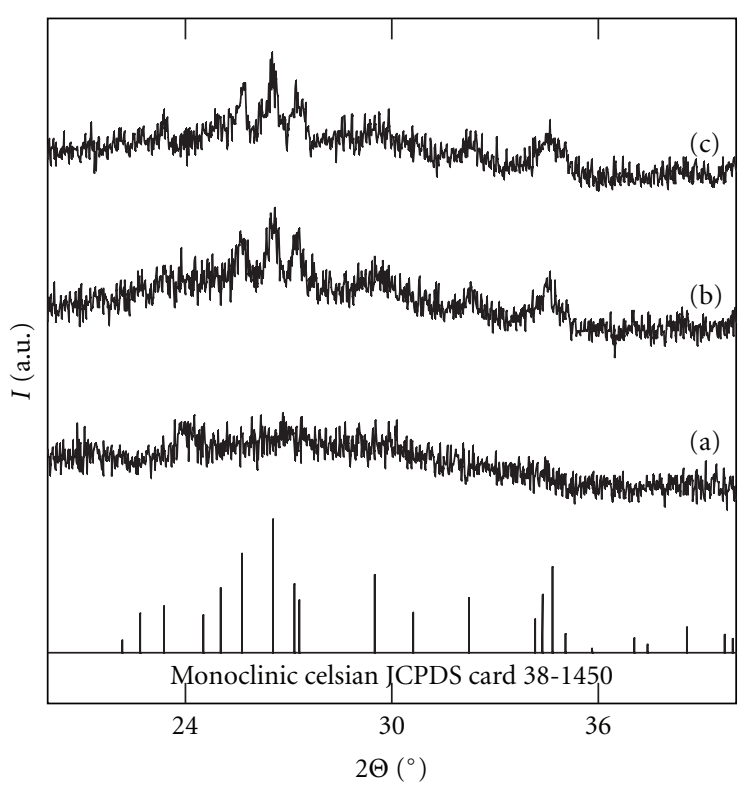

FIGURE 1: XRD patterns of sample 1 thermally treated at $200^{\circ} \mathrm{C}$ for 2 hours (a), heated at $500^{\circ} \mathrm{C}$ and then cooled down in air atmosphere (b), and thermally treated at $800^{\circ} \mathrm{C}$ for 28 hours (c).

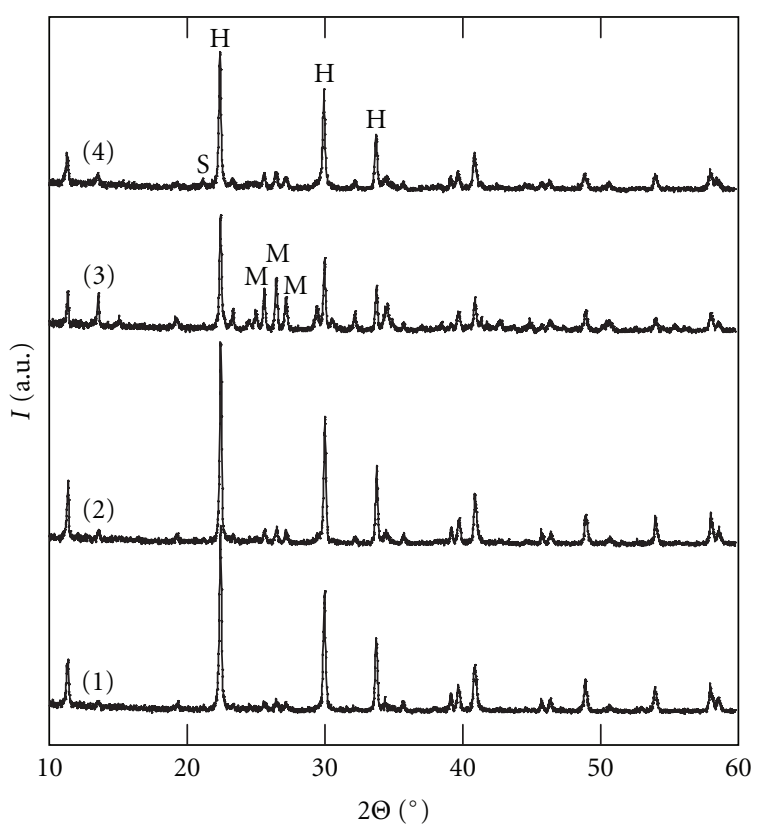

FIGURE 2: XRD patterns of powder-like samples 1, 2, 3, and 4 thermally treated at $1000^{\circ} \mathrm{C}$ for 5 hours $(\mathrm{M}=$ monoclinic celsian, $\mathrm{H}=$ hexacelsian, $\mathrm{S}=$ sodium aluminosilicate).

monoclinic celsian increases with increasing the temperature and duration time of thermal treatment, all other conditions being equal.

XRD patterns of samples 1, 2, 3, and 4 thermally treated at $1300^{\circ} \mathrm{C}$ for 5 hours are reported in Figure 3 . In this same figure, the XRD patterns of the materials obtained by 


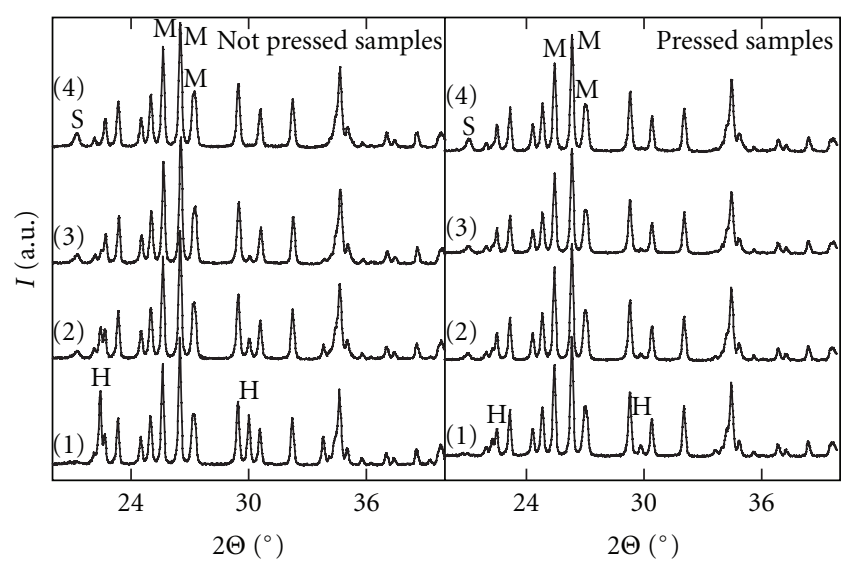

FIGURE 3: XRD patterns of powder-like samples 1, 2, 3, and 4 and of materials obtained by grinding pellets manufactured by pressing samples $1,2,3$, and 4 at $30 \mathrm{MPa}$, thermally treated at $1300^{\circ} \mathrm{C}$ for 5 hours $(\mathrm{M}=$ monoclinic celsian, $\mathrm{H}=$ hexacelsian, $\mathrm{S}=$ sodium aluminosilicate).

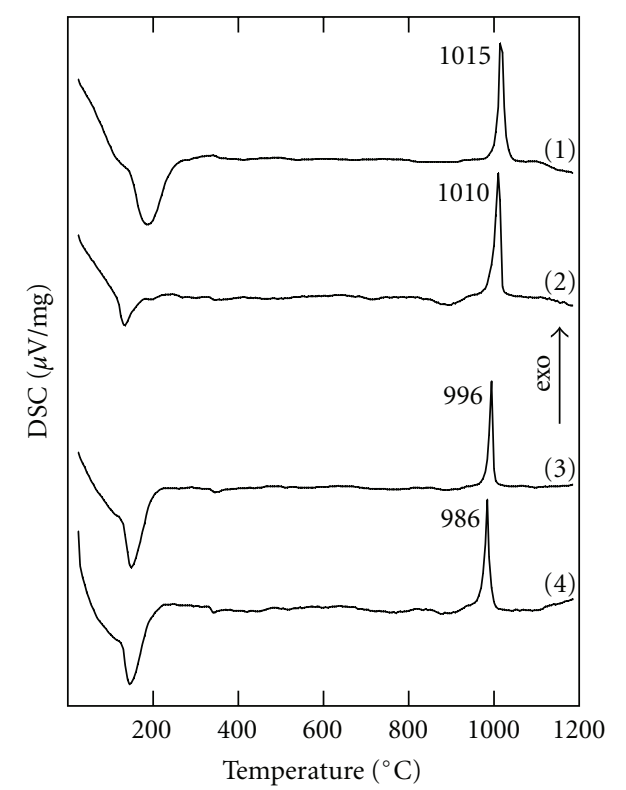

Figure 4: DTA curves for the samples 1, 2, 3, and 4.

grinding the cylindrical pellets previously prepared by cold pressing at $30 \mathrm{MPa}$ samples 1, 2, 3, and 4 and then subjected to the thermal cycle described in experimental are reported.

In these XRD patterns, the diffraction peaks of monoclinic celsian appear together with those of hexacelsian. The intensity of peaks of hexacelsian steadily decreases and the intensity of peaks of monoclinic celsian steadily increases with increasing the $\mathrm{Na}$ residual content of $\mathrm{Ba}$ exchanged zeolite A samples. In Figure 3 the presence of diffraction peaks of hexacelsian can be hardly detected in XRD pattern of Ba-exchanged zeolite A samples exhibiting the highest $\mathrm{Na}$ residual content. It must be noticed that in the X-ray diffraction pattern of samples 2, 3, and 4, a very low intensity peak indicating the presence of an extremely small amount of sodium aluminosilicate $\mathrm{NaAlSiO}_{4}$, may be detected, regardless of the fact that the thermal treatment was performed on a powder or on a previously pressed pellet. Obviously, the intensity of this peak appears to increase with increasing $\mathrm{Na}$ content. Finally, it appears noteworthy that the intensity of peaks of monoclinic celsian is higher and the intensity of peak of hexacelsian is lower in the XRD patterns of the powders obtained by grinding the pellets than in the XRD patterns of the powder-like Ba-exchanged zeolite A samples, all other conditions being equal. The XRD patterns of the materials obtained by grinding the cylindrical pellets previously prepared by cold pressing at $60 \mathrm{MPa}$ samples 1,2 , 3 , and 4 and then subjected to the thermal cycle described in experimental, are not reported, as they did not sensibly differ from those of the materials obtained by grinding the cylindrical pellets previously prepared by cold pressing at $30 \mathrm{MPa}$ samples 1, 2, 3, and 4 .

XRD patterns of powder-like samples 1, 2, 3, and 4 thermally treated at $1300^{\circ} \mathrm{C}$ for 10 and 15 hours are not reported inasmuch as they resemble the XRD patterns of homologous powder-like samples reported in Figure 3, although they clearly denote that the intensity of peaks of hexacelsian decreases and the intensity of peaks of monoclinic celsian increases with increasing the duration time of thermal treatment, with all other conditions being equal. Even in such XRD patterns, the intensity of diffraction peaks of monoclinic celsian increases and the intensity of peaks of hexacelsian decreases with increasing the Na residual content of Ba-exchanged zeolite A samples. In particular, the presence of diffraction peaks of hexacelsian can be very hardly detected in XRD pattern of samples 1 and 2 thermally treated at $1300^{\circ} \mathrm{C}$ for 10 hours and of sample 1 thermally treated at $1300^{\circ} \mathrm{C}$ for 15 hours, whereas completely disappeared in the remaining XRD patterns.

XRD patterns of samples $1,2,3$, and 4 thermally treated at 1400 and $1500^{\circ} \mathrm{C}$ for 5 hours are not reported inasmuch as they very closely resemble the XRD pattern of homologous samples thermally treated at $1300^{\circ} \mathrm{C}$ for 5 hours, thus indicating that the temperature of thermal treatment does not play a crucial role for temperatures higher than $1300^{\circ} \mathrm{C}$.

3.3. Thermal Analysis. Figure 4 reports the DTA curves of samples $1,2,3$, and 4 . In all curves a large low-temperature endothermic effect and a sharp high-temperature exothermic effect may be recorded. The large low-temperature endothermic effect, which attains its minimum at about $180^{\circ} \mathrm{C}$, is related to the progressive dehydration of zeolite A upon heating followed by the thermal collapse of the microporous zeolite structure with the formation of an amorphous phase. This finding is in agreement with the XRD data which reveals that when thermally treated at $200^{\circ} \mathrm{C}$ for 2 hours, the various samples result in a completely amorphous phase (Figure 1). The sharp high-temperature exothermic effect, which can be reasonably ascribed to the crystallization of hexacelsian from the amorphous phase, occurs at temperatures, ranging between 986 and $1015^{\circ} \mathrm{C}$, which steadily decrease with increasing $\mathrm{Na}$ content. Even this finding is in agreement with the XRD data which reveal 
that equal thermal treatments of various samples in the temperature range $800-1100^{\circ} \mathrm{C}$ result in the crystallization of hexacelsian from the amorphous phase and that the extent to which such crystallization occurs steadily increases with increasing $\mathrm{Na}$ content. Evidence of the sluggish hexacelsian $\rightarrow$ monoclinic celsian transition may not be found in the DTA curves of various samples.

\section{Discussion}

The careful inspection of the data here reported confirms the results of previous studies [14, 18-25]. In particular, the sequence of thermal transformations of Ba-exchanged zeolite A (zeolite $\rightarrow$ amorphous phase $\rightarrow$ hexacelsian $\rightarrow$ monoclinic celsian) and the formation of small crystallites of monoclinic celsian prior to the crystallisation of hexacelsian, which expedite the subsequent conversion of hexacelsian into monoclinic celsian, were confirmed. The strong mineralizing action developed by $\mathrm{Na}$, envisaged in previous work $[14,18-25]$, is confirmed on the basis of the considerations that will be hereafter reported. Actually small increases of $\mathrm{Na}$ residual content result in a steady decrease of the temperature at which the crystallization of hexacelsian from the amorphous phase, arising from the thermal collapse of the microporous zeolite structure, occurs (see Figure 4). Then small increases of $\mathrm{Na}$ residual content result in sensible decreases of temperatures and times needed to attain the full conversion of hexacelsian to monoclinic celsian for thermal treatments at temperatures not lower than $1300^{\circ} \mathrm{C}$. As far as the thermal treatments in the temperature range 1000$1200^{\circ} \mathrm{C}$ are concerned, the extent to which the conversion of hexacelsian in monoclinic occurs attains a maximum for sample 3 that exhibits $0.58 \mathrm{meq} / \mathrm{g}$ Na residual content. This seeming inconsistency may be explained considering that, in this temperature range, the crystallization of a small amount of low carnegieite $\mathrm{NaAlSiO}_{4}$ occurs only in sample 4, which exhibits the highest $\mathrm{Na}$ residual content $(0.74 \mathrm{meq} / \mathrm{g})$, at a temperature as low as $1000^{\circ} \mathrm{C}$ (see Figure 2). The Na present in this phase does not appear available to promote other phase transformations such as the conversion of hexacelsian to monoclinic celsian. The extent of the conversion of hexacelsian in monoclinic celsian steadily increases with increasing $\mathrm{Na}$ residual content when the temperature of thermal treatments is not lower than $1300^{\circ} \mathrm{C}$. Actually such thermal treatment promotes the crystallization of a small amount of low carnegieite $\mathrm{NaAlSiO}_{4}$ even in samples 2 and 3 at $1300^{\circ} \mathrm{C}$. Moreover, the strong mineralizing role of $\mathrm{Na}$ is confirmed by the fact that for $\mathrm{Na}$ residual contents not lower than $0.27 \mathrm{meq} / \mathrm{g}$, the temperature of the thermal treatment, if higher than $1300^{\circ} \mathrm{C}$, does not play a crucial role in the thermal transformations of Ba-exchanged zeolite A.

Another point that appears worth to be stressed is that the amount of monoclinic celsian is higher and the amount of hexacelsian is lower in all the materials obtained by grinding the pellets than in the powder-like Ba-exchanged zeolite A samples, all other conditions being equal (see Figure 3 ). This finding could be interpreted bearing in mind that pressing the powder-like samples of Ba-exchanged zeolite A to manufacture cylindrical pellets gives rise to an increase in the contact surface among the grains of hexacelsian. This fact could likely make easier and expedite the conversion of hexacelsian into monoclinic celsian in the case this phase transition starts on the surface of grains of hexacelsian rather than in their bulk. An increase in the forming pressure from 30 to $60 \mathrm{MPa}$ does not result in a further increase of the reactivity of the system, presumably because the increase in the contact surface among the grains of hexacelsian, related to such increase in forming pressure, does not occur to a very large extent. These findings are in agreement with the literature, as it was found that forming pressures up to $50 \mathrm{MPa}$ promote a densification process, due to the grains deformation which produces a decrease of porosity [32]. Forming pressures higher than $50 \mathrm{MPa}$ do not further improve the densification process [32].

The increase in the reactivity of the system arising from pressing powder-like samples of Ba-exchanged zeolite A samples to obtain cylindrical pellets has another important consequence. Actually an inspection of the data of this paper reveals that thermally treating at $1300^{\circ} \mathrm{C}$ for 5 hours samples of Ba-exchanged zeolite $\mathrm{A}$ with $\mathrm{Na}$ residual content higher than $0.27 \mathrm{meq} / \mathrm{g}$ previously pressed at $30 \mathrm{MPa}$ to obtain cylindrical pellets, results in final products almost totally made up by monoclinic celsian with a very low amount of hexacelsian. This finding appears of great interest from the point of view of practical applications inasmuch as the presence of not more than $10 \%$ weight of hexacelsian does not result in a sensible reduction of the technological properties of celsian [1]. This fact allows to envisage that thermally treating at $1300^{\circ} \mathrm{C}$ for 5 hours samples of Baexchanged zeolite $\mathrm{A}$ with a residual $\mathrm{Na}$ content higher than $0.27 \mathrm{meq} / \mathrm{g}$, has potential for practical application in the manufacture of celsian-based ceramics.

\section{Conclusions}

The results of this work confirm the sequence of thermal transformations that Ba-exchanged zeolite A undergoes (zeolite $\rightarrow$ amorphous phase $\rightarrow$ hexacelsian $\rightarrow$ monoclinic celsian) $[14,18-25]$ and the strong mineralizing action developed by $\mathrm{Na}$. Moreover, the fact that pressing the $\mathrm{Ba}-$ exchanged zeolite A powder-like samples to obtain cylindrical pellets which expedite the sluggish final phase transition hexacelsian $\rightarrow$ monoclinic celsian is revealed.

Nevertheless, the results of this work infer further interesting considerations concerning the optimum residual $\mathrm{Na}$ content of Ba-exchanged zeolite A to be transformed into monoclinic celsian. Actually the results of this work seem to supply strong indication that such optimum $\mathrm{Na}$ residual content ranges between 0.27 , and $0.43 \mathrm{meq} / \mathrm{g}$. The considerations that suggested this conclusion are the following.

(1) $\mathrm{Na}$ residual contents lower than $0.27 \mathrm{meq} / \mathrm{g}$ result in high temperatures and/or long thermal treatment times to transform hexacelsian into monoclinic celsian (as an example the completion of this transformation was attained by thermally treating at 1300,1400 , and $1500^{\circ} \mathrm{C}$ for 22,15 , and 22 hours, 
respectively, a sample of Ba-exchanged zeolite A with a $0.20 \mathrm{meq} / \mathrm{g}$ Na residual content) [18].

(2) Na residual content not lower than $0.43 \mathrm{meq} / \mathrm{g}$ may result in the formation of amounts of sodium aluminosilicate $\mathrm{NaAlSiO}_{4}$ exhibiting low melting temperature, sufficient to negatively affect the good technological properties of celsian-based ceramics.

(3) On the basis of the results reported in this paper it may be said that a 5-hour thermal treatment at $1300^{\circ} \mathrm{C}$ of a pellet obtained by pressing at $30 \mathrm{MPa} \mathrm{Ba}-$ exchanged zeolite A samples with a residual $\mathrm{Na}$ content ranging between 0.27 and $0.43 \mathrm{meq} / \mathrm{g}$ results in a product mostly made up by monoclinic celsian which should presumably exhibit the good technological properties typical of celsian-based ceramics. Actually the amount of hexacelsian, (presumably lower than $10 \%$ weight), and the very small amount of sodium aluminosilicate $\mathrm{NaAlSiO}_{4}$ possibly present in the final product together with monoclinic celsian, do not appear able to sensibly affect the good technological properties of celsian-based ceramics.

\section{Acknowledgment}

This work was carried out with the financial contribution of the (MIUR) Ministero dell'Istruzione dell'Università e della Ricerca.

\section{References}

[1] I. G. Talmy, D. A. Haught, and E. J. Wuchina, "Ceramics in the system $\mathrm{BaO} \cdot \mathrm{Al}_{2} \mathrm{O}_{3} \cdot 2 \mathrm{SiO}_{2}-\mathrm{SrO} \cdot \mathrm{Al}_{2} \mathrm{O}_{3} \cdot 2 \mathrm{SiO}_{2}$ (BAS-SAS). Polymorphism, processing and properties," in Proceedings of the International SAMPE Electronics Conference, vol. 6, pp. 687-698, June 1992.

[2] N. P. Bansal and C. H. Drummond III, "Kinetics of Hexacelsian-to-Celsian phase transformation in $\mathrm{SrAl}_{2} \mathrm{Si}_{2} \mathrm{O}_{8}$," Journal of the American Ceramic Society, vol. 76, no. 5, pp. 1321-1324, 1993.

[3] N. P. Bansal, "Solid state synthesis and properties of monoclinic celsian," Journal of Materials Science, vol. 33, no. 19, pp. 4711-4715, 1998.

[4] G. Gouadec, P. Colomban, and N. P. Bansal, "Raman study of uncoated and $\mathrm{p}$-BN/SiC-coated Hi-Nicalon fiber-reinforced Celsian matrix composites," NASA Technical Memorandum 210349, 2000.

[5] N. P. Bansal, "Ceramic fiber reinforced glass-ceramic matrix composite," US patent no. 5,214,004, 1993.

[6] N. P. Bansal, "Method of producing a silicon carbide fiber reinforced strontium aluminosilicate glass-ceramic matrix composite," US patent no. 5,389,321, 1995.

[7] N. P. Bansal, "Solid state synthesis and properties of monoclinic Celsian," NASA Technical Memorandum 107355, 1996.

[8] N. P. Bansal and J. A. Setlock, "Fabrication of fiber-reinforced Celsian matrix composites," NASA Technical Memorandum 210216, 2000.

[9] J. Z. Gyekenyesi and N. P. Bansal, "High temperature tensile properties of unidirectional Hi-Nicalon/Celsian composites in air," NASA Technical Memorandum 210214, 2000.
[10] N. P. Bansal and J. I. Eldridge, "Effects of fiber/matrix interface and its composition on mechanical properties of HiNicalon/Celsian composites," NASA Technical Memorandum 209057, 1998.

[11] N. P. Bansal, "Strong and tough Hi-Nicalon-fiber-reinforced celsian-matrix composites," Journal of the American Ceramic Society, vol. 80, no. 9, pp. 2407-2409, 1997.

[12] I. G. Talmy and D. A. Haught, "Method of preparing monoclinic $\mathrm{BaO} \cdot \mathrm{Al}_{2} \mathrm{O}_{3} \cdot 2 \mathrm{SiO}_{2}$," US patent no. 5,695,725, 1997.

[13] R. Cass, G. Eadon, and P. Wentzel, "Processing and properties of fiber reinforced barium aluminosilicate composites for high temperature radomes," Ceramic Engineering and Science Proceedings, vol. 29, no. 2, pp. 179-187, 2009.

[14] G. Dell'Agli, C. Ferone, M. C. Mascolo, and M. Pansini, "Thermal transformation of Ba-exchanged $\mathrm{A}$ and $\mathrm{X}$ zeolites into monoclinic celsian," Solid State Ionics, vol. 127, no. 3, pp. 309-317, 2000.

[15] H. C. Lin and W. R. Foster, "Studies in the system $\mathrm{BaO}-$ $\mathrm{Al}_{2} \mathrm{O}_{3}-\mathrm{SiO}_{2}$, I. The polymorphism of celsian," American Mineralogist, vol. 53, pp. 134-144, 1968.

[16] M. Chen, W. E. Lee, and P. F. James, "Preparation and characterisation of alkoxide-derived celsian glass-ceramic," Journal of Non-Crystalline Solids, vol. 130, no. 3, pp. 322-325, 1991.

[17] B. Hoghooghi, J. McKittrick, E. Helsel, and O. A. Lopez, "Microstructural development, densification, and hot pressing of celsian ceramics from ion-exchanged zeolite precursors," Journal of the American Ceramic Society, vol. 81, no. 4, pp. 845$852,1998$.

[18] C. Ferone, G. Dell'Agli, M. C. Mascolo, and M. Pansini, "New insight into the thermal transformation of barium-exchanged zeolite A to celsian," Chemistry of Materials, vol. 14, no. 2, pp. 797-803, 2002.

[19] A. Aronne, S. Esposito, C. Ferone, M. Pansini, and P. Pernice, "FTIR study of the thermal transformation of bariumexchanged zeolite A to celsian," Journal of Materials Chemistry, vol. 12, no. 10, pp. 3039-3045, 2002.

[20] S. Esposito, C. Ferone, M. Pansini, L. Bonaccorsi, and E. Proverbio, "A comparative study of the thermal transformations of Ba-exchanged zeolites A, X and LSX," Journal of the European Ceramic Society, vol. 24, no. 9, pp. 2689-2697, 2004.

[21] N. J. Clayden, S. Esposito, C. Ferone, and M. Pansini, " ${ }^{29}$ SI and ${ }^{27} \mathrm{Al} \mathrm{NMR}$ study of the thermal transformation of barium exchanged zeolite-A to celsian," Journal of Materials Chemistry, vol. 13, no. 7, pp. 1681-1685, 2003.

[22] C. Ferone, S. Esposito, G. Dell'Agli, and M. Pansini, "Role of $\mathrm{Li}$ in the low temperature synthesis of monoclinic celsian from (Ba, Li)-exchanged zeolite-A precursor," Solid State Sciences, vol. 7, no. 11, pp. 1406-1414, 2005.

[23] F. Andreola, M. Romagnoli, C. Siligardi, T. Manfredini, C. Ferone, and M. Pansini, "Densification and crystallization of Ba-exchanged zeolite A powders," Ceramics International, vol. 34, no. 3, pp. 543-549, 2008.

[24] S. Ronchetti, E. A. Turcato, A. Delmastro et al., "Study of the thermal transformations of $\mathrm{Co}$ - and $\mathrm{Fe}$-exchanged zeolites $A$ and X by "in situ" XRD under reducing atmosphere," Materials Research Bulletin, vol. 45, no. 6, pp. 744-750, 2010.

[25] C. Ferone, B. Liguori, A. Marocco, S. Anaclerio, M. Pansini, and C. Colella, "Monoclinic (Ba, Sr)-celsian by thermal treatment of (Ba, Sr)-exchanged zeolite A," Microporous and Mesoporous Materials, vol. 134, no. 1-3, pp. 65-71, 2010.

[26] M. A. Subramanian, D. R. Corbin, and R. D. Farlee, "X-ray and MAS NMR characterization of the thermal transformation 
of $\mathrm{Li}(\mathrm{Na}) / 1 \mathrm{bY}$ zeolite to lithium aluminosilicates," Materials Research Bulletin, vol. 21, no. 12, pp. 1525-1532, 1986.

[27] U. V. Chowdry, D. R. Corbin, and M. A. Subramanian, "Anorthite-cordierite based ceramics from zeolites," US patent no. $4,814,303,1989$.

[28] M. A. Subramanian, D. R. Corbin, and U. V. Chowdry, "Zeolites as precursors to alluminosilicate based ceramics for microelectronic packaging," Advanced Ceramics, vol. 26, pp. 239-247, 1989.

[29] D. R. Corbin, J. B. Parise, U. V. Chowdry, and M. A. Subramanian, "Designing zeolites as novel precursors to electronic ceramics," in Proceedings of the Materials Research Society Symposium, vol. 233, Pittsburgh, Pa, USA, 1991.

[30] D. W. Breck, Zeolite Molecular Sieves: Structure, Chemistry and Use, John Wiley \& Sons, New York, NY, USA, 1974.

[31] G. Schwarzenbach and H. Flaschka, Complexometric Titration, Methuen, London, UK, 1969.

[32] J. S. Reed, Introduction to the Principle of Ceramic Processing, John Wiley \& Sons, New York, NY, USA, 1988. 

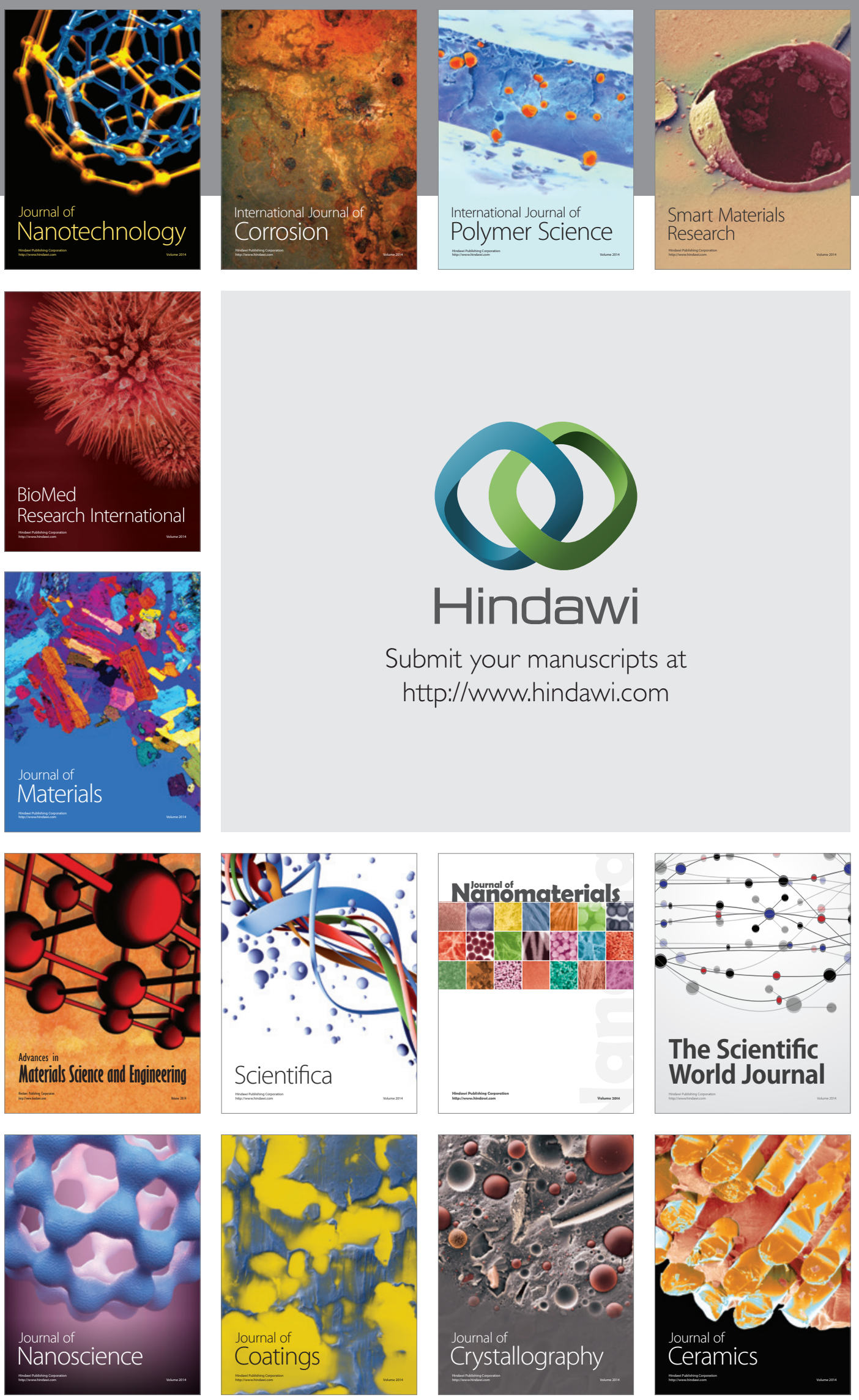

The Scientific World Journal

Submit your manuscripts at

http://www.hindawi.com

\section{World Journal}

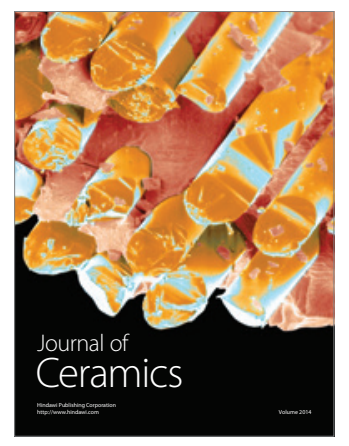

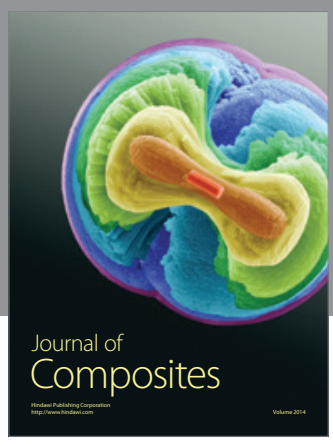
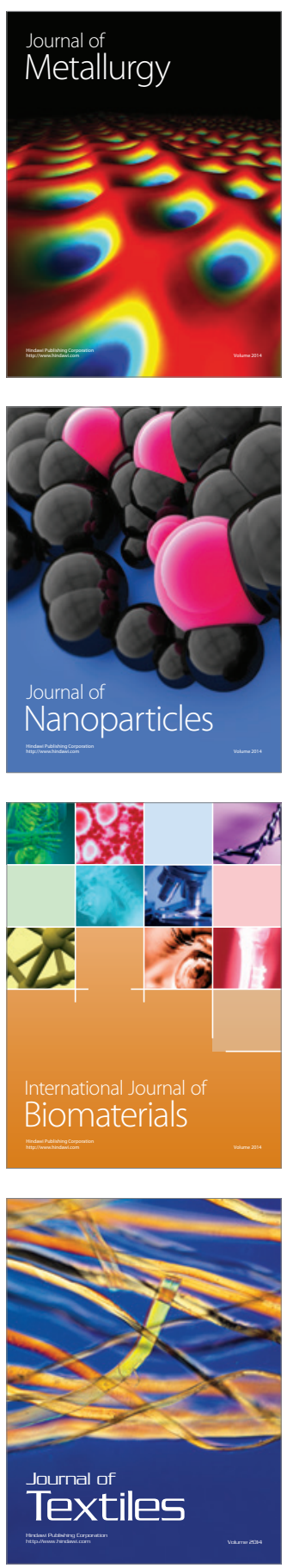